\title{
O AJUSTE NEOLIBERAL CONTRA A DEMOCRACIA SOCIAL: O CONTEXTO DE 2015-2016, NO BRASIL ${ }^{1}$
}

\author{
Neoliberal adjustment against social democracy: the context of 2015-2016, \\ in Brazil
}

Anete B. L. Ivo (UCSal/UFBA)

Informações do artigo

Recebido em 01/04/2017.

Aceito em 30/04/2017.

\begin{abstract}
Resumo
O artigo examina os fatores políticos de um liberalismo social apoiado nos programas de transferência de renda (PTR) e como esses influenciam a legitimidade dos governos e a subjetividade dos beneficiados. Parte da hipótese de que a reinvestida neoliberal do presente atua sobre os pilares políticos das teses neoliberais, implicando rupturas institucionais, crise social e de confiança entre os cidadãos e o Estado. Essa investida recente, no Brasil, alimenta-se do golpe parlamentar no polêmico impeachment da Presidente, sem crime de responsabilidade configurado, desrespeitando a soberania do voto popular. Segue-se um processo de desconstrução institucional dos direitos sociais constitucionais e a desregulação do patrimônio público e naturais em favor das corporações econômicas nacionais pelo novo governo, produzindo um "fascismo social", segundo Santos (2016), quando o regime democrático aprofunda uma grave exclusão social.
\end{abstract}

Palavras-Chave: Neoliberalismo; Impeachment Dilma. Programas de Transferência de Renda. Reformas sociais. Crise política e institucional.

\begin{abstract}
This article examines the political factors of a social liberalism supported by cash transfer programs and how they influence the legitimacy of governments and the subjectivity of the beneficiaries. It is based on the assumption that the current neoliberal attack acts upon the political cornerstones of the neoliberal ideology, causing a break with institutional ties, a social crisis and a crisis of confidence between citizens and the State. This recent attack, in Brazil, has been nourished by the parliamentary coup, the impeachment of the President with no constituted abuse of office, disrespecting the sovereignty of the vote. What followed was a process of institutional dismantlement of the social constitutional rights and the deregulation of public and natural assets in favor of national economic corporations by the new government, creating a "social fascism", that according to Santos (2016), happens when the democratic regime deepens social exclusion.

Keywords: Neoliberalism. Impeachment Dilma. Cash Transfer Programs. Social Reforms. Political Crisis; Institutional Crisis.
\end{abstract}

1 Esse artigo foi escrito originalmente em maio de 2016 e revisto em novembro de 2016, após o impeachment sem mérito constitucional da Presidente Dilma Rousseff, em 31.08.2016, sob o título "Caminho de volta: o ajuste contra a democracia social", apresentado no Seminário "Nuevas (y Antiguas) Estructuraciones de las Políticas Sociales en $A L^{\prime \prime}$.Montevideo, CLACSO e Facultad de Ciencias Sociales, Universidad de La Republica, 2-4 de maio de 2016. Discute o início da crise política e institucional de impeachement da Presidente Dilma, que implanta reformas antipopulares na área social, pelo governo Michel Temer, e a desregulação do patrimônio público nacional dos bens naturais para corporações econômicas internacionais, seguidas por inescrupulosas concessões ao agronegócio, feitas pelo Presidente a parlamentares da Câmara, de forma a escapar às denúncias de corrupção encaminhadas pela Procuradoria Geral da União. 
As políticas sociais constituem-se mediadores institucionais que atenuam as assimetrias entre a sociedade e mercado, com vistas a reduzir as desigualdades e garantir seguridade econômica como direitos da cidadania, num regime capitalista. Elas integram um projeto de justiça social, de caráter redistributivo e fundam, ao mesmo tempo, parte da legitimação política e social dos governos. A forma de intervenção pública na área social, no entanto, não é técnica e sofrem constantemente a polarização política entre os que defendem maior distribuição da renda, no sentido dos direitos da cidadania, ou maior liberação do mercado.

Esse artigo discute as relações contraditórias entre economia e política na gestão das políticas sociais, observando os fatores políticos inerentes a um liberalismo social baseado na implantação dos programas de transferência de renda condicionada no Brasil. Indaga que fatores políticos determinam esse novo modelo e como esse favorece uma grande legitimidade dos governos junto às camadas populares e como a experiência de vivência institucional desses programas alteram a subjetividade da cidadania. O artigo finaliza discutindo o contexto inicial do segundo mandato da presidente Dilma, em 2015, que marca uma grave inflexão nos pilares da democracia, no Brasil, caracterizada pelo impeachment da Presidente da República, por um golpe parlamentar sem crime de responsabilidade, que implicou a desconstrução dos pilares constitucionais do Estado social brasileiro e um processo de desregulação dos bens naturais e públicos em favor das grandes corporações econômicas estrangeiras. Conclui que a prevalência radical da agenda neoliberal caracteriza o que Boaventura de Souza Santos (2016) chama de "fascismo social", quando o regime democrático formal dissocia-se das condições efetivas de inclusão social e política, aprofundado processos de exclusão e dessocialização social de uma grande maioria da população.

\section{Algumas tensões entre economia e política, sob hegemonia neoliberal}

Desde o início dos anos oitenta fala-se da crise do Estado de bem-estar, nos países centrais. Essa crise expressa a difícil conciliação entre um regime de acumulação globalizado e um sistema democrático dos países que envolvem direitos sociais da cidadania e redistribuição de renda. Na realidade, a crise expressa assimetrias entre a capacidade de inclusão social, num contexto de remercantilização de todas as esferas da vida, sob 
prevalência do mercado. Portanto, ela contém uma polarização entre forças políticas que postulam por um maior ou menor grau de desmercantilização ${ }^{2}$ da força de trabalho, questão necessariamente tensa e fonte de conflito permanente entre interesses de classes divergentes.

Desde a década de 50 os liberais resistem às políticas redistributivas do Welfare porque consideravam que elas ameaçavam o crescimento estável. No entanto, o crescimento acelerado da economia, à época, neutralizou parte dessas resistências. Na década de 60 a esquerda, insatisfeita com os resultados em matéria de "igualdade", pressionou os Estados para ampliação da cobertura e expansão generalizada de direitos sociais (ESPINGANDERSEN, 2000, p. 18)3.

Em meados da década de 70, diante da crise de crescimento nos países centrais, o diagnóstico conservador da governabilidade para a América Latina ${ }^{4}$ recomendou ajustes institucionais nos Estados em favor do mercado, apontando o deficit fiscal das economias nacionais como o eixo da crise, entendida, pelos neoliberais, como incapacidade dos governos de responderem às pressões e demandas sociais progressivas e pela intervenção excessiva do Estado na economia. A essa tese econômica e fiscal, arguida pelos setores neoliberais, eles associam teses políticas, como crise de autoridade dos governos; o provincianismo dos Estados nacionais; e o excesso de democracia (!!!), fatores que, segundo o relatório The crises of democracy (1975), produzem crises cíclicas de crescimento econômico e obstáculos à livre circulação do mercado. Essas teses neoliberais foram ratificadas na conferência internacional da OCDE5- Organização para a Cooperação e Desenvolvimento Econômico (1981), por Robert R. Higgins (1983), ao concluir que o estancamento econômico,

2 Corresponde à expressão "decommodification" usada por Gosta Esping-Ansersen (1990). Tenho traduzido a expressão como "desmercantilização da força de trabalho" (IVO, 2004), que significa o acesso dos trabalhadores a seguros e prestações sociais, baseados em direitos e políticas sociais, que expressam um processo parcial de socialização da economia.

3 Essa tendência teve efeitos sobre países em desenvolvimento e se expressou em intensas mobilizações sociais nas décadas de setenta e oitenta. O resultado desses movimentos no Brasil se traduziu na expansão de direitos sociais básicos de cidadania inscritos na Constituição Brasileira de 1988, como a Previdência Especial Rural e o Benefício da Prestação Continuada, além de outros benefícios de reconhecimento dos direitos das minorias.

4 Sobre o diagnóstico conservador da governabilidade, ver Huntington; Crozier; Watanuki (1975). Resumi as principais teses econômicas e políticas desse documento em Ivo (2001, p. 48-49), mostrando como as medidas de ajuste fiscal associam-se teses e ações restritivas à democracia, especialmente para países da América.

5 Organisation for Economic Co-operation and Development [OECD]. 
a inflação e o crescente desemprego tinham origem nos excessivos encargos dos Estados nacionais.

A magnitude da crise econômica e política no presente nos leva à hipótese de que o diagnóstico conservador da governabilidade dos anos 1975, que fundamentou a reforma institucional do Estado em favor do mercado, nos anos noventa, não conseguiu avançar sobre os pilares políticos no âmbito interno do país, dada a mobilização da sociedade brasileira em favor de um projeto democrático e a grande legitimidade alcançada pelos governos do presidente Lula da Silva, em todos os setores e com amplo apoio dos setores populares. No entanto, confrontadas a uma crise estrutural e sistêmica do capitalismo, as forças econômicas neoliberais intervêm de forma radical sob os pilares políticos das democracias, nos países, aprofundando as teses antidemocráticas na desconstrução dos direitos sociais e na transferência de bens públicos nacionais para grandes corporações econômicas, especialmente em relação ao controle sobre as reservas naturais e fontes de energia.

Efetivamente, a implantação do regime de Seguridade Social no Brasil, como política de Estado nos anos noventa, ocorreu na contramão das tendências internacionais de desregulação do Estado de Bem-estar social e liberalização dos mercados, configurando, internamente, uma assimetria política entre o reconhecimento de direitos políticos, civis e sociais conquistados pela Constituição de 1988, de um lado, e, uma reengenharia do Estado e ajustes institucionais, por outro, que pressiona para uma regressão dos direitos sociais e políticos, na desqualificação das esferas públicas.

A implementação de programas na área social, a partir de 2004 , especialmente os programas de transferência de renda (PTR) e as acomodações estratégicas no campo da disputa eleitoral ${ }^{6}$, num ambiente de crescimento no âmbito mundial, favoreceram a aplicação massiva desses programas sociais de grande capilaridade e abrangência sobre os setores socialmente mais vulneráveis. Esses programas representam um "liberalismo social inclusivo", que envolve mecanismos distributivos, mas focalizados e estratégicos sobre os mais pobres, fora da área crítica do seguro social. A implementação desse liberalismo social dos PTR expressa, na realidade, uma "afinidade eletiva" da agenda da esquerda na luta contra

\footnotetext{
6 No Brasil, a "Carta ao Povo Brasileiro", de 22 de junho de 2002, do então candidato à Presidência da República pelo Partido dos Trabalhadores (PT), Luiz Inácio Lula da Silva, assume tom moderador e acalma o mercado, garantindo um leque maior de apoio à sua candidatura.
} 
as desigualdades, combinada com a agenda liberal focalizada dos programas sociais (da escolha pública estratégica sobre os mínimos sociais) associada a um ativismo do trabalho (empreendedorismo), cuja implementação pode conduzir a regimes de workfare com intensificação e disciplinamento do trabalho em formas precárias.

Essa afinidade eletiva nas políticas sociais para classes populares 7 incluiu tanto as transferências monetárias diretas às famílias, realizadas pelo Programa Bolsa Família (PBF), como um investimento em políticas públicas de inspiração keynesiana, baseadas no aumento contínuo do salário mínimo e na recuperação do emprego formal. Essas intervenções na área social passaram a ser duramente questionado pelas elites econômicas e políticas, e, em 2015, quando a crise da economia brasileira interna encontrou a crise internacional, foram duramente atacadas, no plano institucional, político e ideológico. No âmbito internacional seis dimensões econômica atuaram com repercussão interna: a desaceleração da China, a queda das cotações no preço das commodities, a redução do ritmo de crescimento da economia nos países emergentes, as políticas monetárias nacionais em desalinho, a situação financeira dos bancos dos países centrais e a queda das bolsas, em particular nos EUA. (DIEESE, 2016).

Os efeitos da crise econômica internacional refletiram-se numa polarização política entre dois projetos: um de natureza mais redistributiva promovido por setores da centroesquerda, e materializado nos mandatos do Partido dos Trabalhadores, e, outro sob hegemonia do mercado, que radicalizou reformas ultraliberais, na destituição do pilar constitucional dos direitos sociais e trabalhistas, no Brasil ${ }^{8}$, avançando, na sequência, na privatização dos bens naturais e públicos, em favor de corporações econômicas do mercado internacional.

7 Refiro-me ao sentido usual das classes populares como sinônimo da classe trabalhadora ampliada, para além dos segmentos do emprego formal, incluindo amplos segmentos sociais cuja reprodução social baseia-se em bens materiais escassos e precários, e grande resiliência. Paulo Freire dá a essa noção a conotação de "oprimido", ou seja, de classes que vivem em condições elementares da cidadania, reconhecendo uma cultura própria do povo.

${ }^{8}$ Trata-se do programa do PMDB sintetizado no documento "Uma ponte para o futuro (FUNDAÇÃO..., outubro 2015). 


\section{Os programas de transferência de renda condicionada (PTR) e seus efeitos no campo da disputa eleitoral}

Nos últimos anos, observa-se, nos países da América latina e em outros da África, a aplicação crescente de programas de transferências condicionadas de renda (PTR), a exemplo do Bolsa Família, no Brasil, e do Oportunidades, no México9. Ao longo de mais de 15 anos, esses programas expandiram-se em 20 países da América Latina, abarcando 136,6 milhões de pessoas, ou seja, alcançaram 21,5\% da população da América Latina e do Caribe e evoluíram de uma irrisória participação do PIB regional, equivalente a 0,06\% em 2000, para quase $0,4 \%$ do PIB regional, em 2013 (CEPAL, 2015). Esses programas consolidam uma modalidade de intervenção dos governos latino-americanos no enfrentamento da pobreza e das desigualdades, desde o início dos anos 2000, e tiveram grande potencial inclusivo das pessoas que integram a faixa de renda mais baixa, favorecendo o consumo das famílias mais pobres. Do mesmo modo, o desenho e a centralidade desses programas alteraram as tradicionais relações entre governo e beneficiários, operando segundo critérios de racionalidade técnica na distribuição de benefícios. Essa matriz altera em parte as relações tradicionais da cultura política clientelista sob comando das velhas oligarquias locais, ainda que essas atuem habilmente, ajustando-se aos novos dispositivos institucionais de gerenciamento da distribuição de benefícios, no âmbito local.

Ao lado da crescente legitimidade social e política desses programas, pelas melhorias do orçamento de milhões de famílias extremamente pobres e do reconhecido desempenho institucional do Programa Bolsa Família (PBF), no Brasil, durante os três mandatos do PT foram adotadas também políticas estruturais de inspiração keynesiana, de emprego e renda, que contribuíram de forma mais robusta para a redução da pobreza e das desigualdades de renda, no país, a exemplo dos aumentos do salário mínimo e da formalização dos postos no mercado de trabalho. No campo político, esses PTR tiveram efeitos distintos segundo regiões e segmentos sociais, com uma grande aceitação nas classes populares, na região Nordeste, e uma enorme rejeição entre os segmentos médios e as elites da região Sudeste, que

9 Em diversos países da região, outros programas também alcançaram altíssimos níveis de cobertura social, a exemplo do: Seguro Popular no México; Jefes y Jefas de Hogares Desocupados y Familia por la Inclusión Social [Argentina]; Plan de Equidad [Uruguay], assim como Chile Solidario e, de maneira semelhante, Red Solidaria [El Salvador], um país historicamente excludente. 
envolveu também setores populares, dado o perfil do mercado de trabalho nessas regiões e o grande impacto da opinião pública televisiva sobre os setores de renda mais baixa, no Sudeste.

Pesquisa realizada por Diego Correa (2014) sobre os efeitos desses programas na competição eleitoral em 21 países da América Latina mostra resultados ambivalentes desses programas no comportamento dos eleitores na América Latina, com rearranjo quanto aos resultados finais. Segundo Correa, no caso do Brasil, "o apoio eleitoral ao governo cresce entre beneficiários do programa, ou seja, junto à população mais pobre, mas cai entre aqueles que se opõem a políticas desse tipo, ou seja, principalmente entre as pessoas de classe média e alta". Segundo o autor ...

O mesmo efeito foi observado em todos os países latino-americanos onde o governo investiu em programas de magnitude e visibilidade similar ao Bolsa Família. Nas eleições brasileiras de 2006, Lula ganhou votos entre eleitores de classe baixa, mas perdeu aproximadamente o mesmo número entre eleitores de classes mais altas. Prova disso é que ele foi reeleito naquele ano com a mesma proporção nacional de votos que ele obteve em 2002, mas desta vez com uma base eleitoral radicalmente diferente. Alguns autores defendem que a perda de votos entre as classes mais altas é explicada por motivos diferentes, como, por exemplo, a corrupção. O problema é que este fenômeno é observado apenas em países que investiram massivamente em políticas redistributivas semelhantes ao Bolsa Família. Nos outros países, isso não ocorreu (CORREA, 2014).

Que fatores políticos influenciaram a reorientação prioritária desses programas na área social, nos anos recentes? Identificamos três fatores políticos que atuaram na reconversão institucional das políticas sociais em programas assistenciais em favor dos mais pobres: um primeiro fator se constitui do diagnóstico conservador de Huntington, Crozier e Watanuki (1975) encomendado pela comissão trilateral sobre a "democracia na América Latina", apresentado na primeira parte desse artigo, que influenciou, mais tarde, as recomendações do Consenso de Washington para os países, orientadas para a reforma institucional do Estado e otimização dos gastos sociais. Um segundo fator político, refere-se à reorientação pragmática dos partidos da socialdemocracia na Europa, nos anos oitenta, em torno de uma agenda de enfrentamento da pobreza, diante das dificuldades de representação política resultantes da reconfiguração do mercado de trabalho e do papel declinante da classe trabalhadora. 
O argumento central dos partidos socialdemocratas europeus considerava que a reestruturação do mercado de trabalho, com o crescimento do setor de serviços e a transformação de parte da classe trabalhadora em classes médias, teria produzido uma desorganização dos trabalhadores em classe e gerado, por consequência, uma crise de representação dos partidos socialistas, uma vez que esses não conseguiam representar os interesses da grande maioria da sociedade (OFFE, 1984 e 1989; PRZEWORSKI, 1989).

Assim, a reestruturação do mercado de trabalho capitalista teria contribuído para uma crise de representação dos partidos socialdemocratas na competição eleitoral, levandoos a assumirem uma plataforma eleitoral mais pragmática, na Europa, em torno de uma agenda de "luta contra a pobreza", antes mesmo da difusão dessa agenda pelas agências multilaterais, ao final dos anos noventa e dois mil, percebida como uma estratégica política capaz de fazer convergir amplos segmentos sociais e políticos, como analisa Przeworski (1989). Essa agenda possibilitava a formação de um círculo ampliado de adesão política dos eleitores aos partidos de esquerda e sua maior legitimidade pela convergência de diversos atores sociais e políticos, tais como: governos, setores da sociedade civil mobilizados em ações filantrópicas; a Igreja; setores da esquerda e dos movimentos sociais que lutam contra as desigualdades da sociedade capitalista e setores da socialdemocracia.

Um terceiro fator atuou na pactuação de uma agenda internacional de combate à pobreza, ao final dos anos noventa e início dos anos 2000, pelas agências multilaterais (Banco Mundial e PNUD), voltada para minimizar os efeitos dessocializadores dos ajustes fiscais da década de noventa (crescimento do desemprego e empobrecimento dos trabalhadores), num cenário de desemprego de longa duração, reorientando as políticas sociais prioritariamente para a assistência aos mais pobres com base em transferências monetárias diretas às famílias mais vulneráveis. A esses programas foram associadas políticas afirmativas de reconhecimento das minorias e um estímulo ao empreendedorismo com um ativismo pelo trabalho, associado à democratização de acesso a créditos populares a pequenos empresários (trabalhadores) como estratégias de inclusão social.

Essas políticas mobilizam princípios morais de "bom governo" disseminados pelas agências multilaterais, orientando a conduta dos agentes segundo o princípio da "gestão eficiente" dos gastos públicos e da capacidade do Estado (capaciting building) no controle e distribuição dos benefícios sociais, focalizados e estratégicos. O desenho estratégico desses programas reconverte o fundamento universalista dos direitos, da Constituição de 88, para 
uma "escolha pública eficiente" focalizada sobre os mais pobres" (IVO, 2001; 2004). Eles operam dispositivos de controles da elegibilidade e acompanhamento das condicionalidades pelos agentes públicos, responsáveis pela gestão dos programas. A seletividade dos beneficiários (nos limites da linha da pobreza) abarca um contingente expressivo de pessoas, dada a preexistência de uma estrutura de renda profundamente desigual, abarcando uma população de 136,6 milhões de pessoas, na América Latina, e um quarto da população brasileira, mas gera uma ambivalência da noção de universalidade, que passa de um fundamento dos 'direitos da cidadania" para uma perspectiva técnica de cobertura do programa.

\section{A 'afinidade eletiva'10 do liberalismo social inclusivo: consenso das políticas de transferência condicionadas de renda, no Brasil}

Nos dois mandatos do Presidente Lula (2003-2010) e no primeiro mandato da Presidenta Dilma Rousseff (2011-2014), o Programa Bolsa Família expandiu-se e consolidouse, mais que dobrando o gasto público, que passou de $0,2 \%$ a 0,5\% do PIB, aproveitando o ambiente de crescimento econômico ${ }^{11}$. O Programa evoluiu de 3,6 milhões de famílias beneficiadas, em 2003, para alcançar 14 milhões de famílias ou quase 50 milhões de pessoas, em 2014, o que significa que ele agregou, acompanhou e gerenciou cerca de $25 \%$ da população brasileira ${ }^{12}$.

A presidente Dilma Rousseff, ao lado do ex-presidente Lula em cerimônia de comemoração dos dez anos do Programa Bolsa Família (30 de outubro de 2013), avaliou o PBF como muito exitoso e afirmou a natureza e estratégia governamental desse programa: "[...] esta é uma iniciativa emancipadora, porque em vez de fortalecer o Estado, transfere o poder ao cidadão, com quem o Brasil tem uma dívida". E, prossegue: "Bolsa Família não é caridade, e sim uma tecnologia social de distribuição de renda e combate à desigualdade. Aí é que

\footnotetext{
${ }^{10}$ A noção de "afinidade eletiva" destaca a ação recíproca, de atração e combinação entre as duas formações: a religiosa e a econômica na obra de Max Weber [1904-5] A ética protestante e o "espírito do capitalismo. O uso dessa expressão aqui se refere às proximidades e ações recíprocas entre o programa social da esquerda e as normativas da agenda neoliberal.

${ }^{11}$ Trata-se de um complemento na renda familiar relativamente baixo, com valores que em 2016 variavam entre $\mathrm{R} \$ 77,00$ a $\mathrm{R} \$ 340,00$ mensais.

${ }^{12}$ Em abril de 2014 O PBF atendia 14,1 milhões de famílias, para uma população brasileira de 202,7 milhões de pessoas, estimado por cálculos do IBGE. (FSP, 28.08.2014).
} 
está a questão. Renda é poder de compra de quem ganha o Bolsa Família, que tem autonomia para decidir o que compra [...]. À medida que o Bolsa Família transfere renda dessa forma, gera liberdade de escolha, de cidadania e de consideração da pessoa que recebe [o benefício] como cidadão brasileiro". (BRASIL, 2013)

Ao defini-lo como "tecnologia social"13 o discurso presidencial reforça o novo perfil da ação social desses programas, que envolve técnicas de acompanhamento, pedagogias de treinamento e capacitação, levando os beneficiários a uma socialização institucional, em termos de acompanhamento da inscrição em políticas de educação e saúde, em interação com os agentes do governo, além de uma indução à inclusão produtiva e ao papel prioritário das mulheres na corresponsabilidade com esses programas. Essa inclusão das famílias ao programa gera, portanto, novas subjetividades e projeta expectativas crescentes de inclusão, pertencimento e mobilidade social, sobretudo nos jovens beneficiários. Ao reconhecer que o Bolsa Família favorece a "autonomia e a liberdade" das chefes de famílias pelo acesso à renda e à liberdade de compra dos beneficiários, a Presidente reforça a "autonomia" especialmente das mulheres, pelo acesso à renda e ao consumo, reafirmando, assim, uma inclusão social via o mercado, mediado pelas transferências de renda e democratização ao crédito, especialmente para segmentos integrantes das faixas de renda mais baixas, associando esses sujeitos à dinâmica do setor financeiro pelo crédito.

A expansão e eficiência do programa reforça uma racionalidade operacional, abala em parte as lealdades de tipo assistencialista-clientelista, em função dos controles da racionalidade técnica e burocrática dos novos agentes públicos na atribuição de benefícios ${ }^{14}$. A Auditoria do Tribunal de Contas da União ao Programa, em 2006 (BRASIL, 2006), não encontrou correspondência entre a distribuição dos benefícios por municípios e a vinculação

13 O termo "tecnologia social" refere-se a um conjunto de técnicas e metodologias introduzidas no campo institucional e aplicadas para a gestão das populações incluídas em programas de inclusão social e melhoria das condições de vida. São técnicas aplicadas para a elegibilidade, controle, definição do público-alvo etc. que são acompanhadas de normas e pedagogias de ação mescladas a valores morais do "Estado eficiente" (certeza do alvo e justeza da prestação) e de processos continuados de avaliação, que consolidam e reafirmam uma visão compartilhada por vários setores da sociedade civil, dos governos e acadêmicos envolvidos na implementação dessas ações sociais, que legitimam essas ações como as mais eficientes. O resultado produz consensos ampliados.

${ }_{14} \mathrm{Na}$ base local, os 'velhos/novos" agentes mesclam-se, gerando novas capilaridades, a exemplo e alguns estudos qualitativos locais. 
a partido político específico, desmistificando o uso eleitoreiro do programa, denunciado por várias vezes pela oposição na mídia.

A projeção desses programas como 'nova tecnologia' de justiça social e os custos reduzidos na redução das desigualdades fazem com que esse programa se afirme como uma 'inovação' pública na área social, sob hegemonia do mercado: estimula a liberdade e a autonomia dos sujeitos para o consumo (como fala a Presidente) e provê alguma proteção social aos mais vulneráveis fora das áreas críticas da Seguridade social. Esse entendimento reforça um consentimento ampliado entre governo, técnicos, agências multilaterais e beneficiários de programas sociais, formando uma 'comunidade epistêmica'15 favorável a essa modalidade de intervenção na área social, no Brasil, admitida como aquela que melhor produz justiça social, sem desperdícios e orientada para a "eficácia do gasto social", sem comprometer a área crítica da Seguridade Social, que envolve assimetrias entre a renda do trabalho e capital.

Comparando os PTRs com os pilares do welfare, observa-se, portanto, uma separação dos nexos estruturais da redistribuição entre pobreza, trabalho e proteção social, e uma subordinação da norma geral da justiça social aos critérios de seletividade e racionalidade instrumental que fortalece a formação de novas subjetividades dos cidadãos ao mercado, pelo consumo. No entanto, apesar dos resultados positivos desse programa, como analiso em outros trabalhos (IVO, 2001, 2004, 2008), as prestações do programa não se constituem em direito e a noção de universalidade restringe-se a uma percepção técnica de cobertura do público-alvo e não a uma titularidade de direitos da cidadania social.

O reforço à renda dos estratos mais baixos da pirâmide de renda envolveu, além dessas ações, políticas macroestruturais de valorização do salário mínimo, formalização do mercado de trabalho e acesso ao crédito dos setores populares, que democratizaram o acesso à renda, dinamizaram o mercado interno, e, juntas, acabaram por alterar a matriz histórica das desigualdades, com melhoria da renda das frações de renda mais baixas e mobilidade social entre segmentos na base da pirâmide.

\footnotetext{
15 "Comunidade epistêmica", grupo de pessoas que partilham crenças causais, normas e noções de validade no empreendimento de políticas, conforme Peter Haas (1992).
} 
O aumento no valor do salário alcançou as aposentadorias e pensões; a maior formalização do emprego e o estímulo ao crédito das classes populares alavancaram o consumo doméstico os quais contribuíram para o crescimento e a dinamização do mercado interno durante a crise internacional de 2008. Portanto, o êxito das políticas de inserção social pela melhoria da renda não resultou exclusivamente do Bolsa Família, mas da combinação dessas com políticas keynesianas de formalização do mercado de trabalho, aumento do salário mínimo e acesso ao crédito. Decompondo as "Causas da redução das desigualdades na década passada" o IPEA (2012, p. 8) destaca os seguintes fatores: Trabalho (58\%), Previdência (19\%), Bolsa Família (13\%), Benefício de Prestação Continuada (BPC 4\%) e Outras. Ou seja, a inscrição no trabalho tem centralidade na redução dos indicadores de desigualdade.

A combinação híbrida dessas políticas atuou sobre segmentos de renda mais baixa, produzindo o que Jacques Rancière (1996) chama de "mésentente" (dissenso), que mobiliza racionalmente políticas diferentes, mas gera um consenso amplo sobre a validade da política.

O efeito conjugado das ações públicas da assistência, previdência e valorização do mercado de trabalho acabaram por ratificar, simbolicamente, o "acerto" do novo modelo de transferência condicionada de renda às famílias mais pobres, como "a via" mais eficaz de justiça social. A correlação entre a expansão do programa e a queda dos índices de desigualdades reforça a convicção do acerto dessas escolhas estratégicas dos PTR focalizados, deixando menos evidentes os fatores macroestruturais de recomposição do mercado de trabalho e valorização do salário que atuaram decisivamente na alteração da posição dos estratos de renda mais baixos no conjunto da renda brasileira.

O manejo do programa opera, portanto, segundo um princípio de seletividade e focalização na criação de uma rede de proteção aos mais pobres, mas proclama discursos normativos de universalidade de direitos. Os pressupostos morais de 'bom governo' na eficiência técnica alimentam a convicção do acerto, e projeta-se como um "dever ser", ou seja, como norma da ação pública favorável à focalização nos mais pobres e um empreendedorismo e ativação dos trabalhadores, pilares desse novo "liberalismo social" praticado nos últimos anos na América Latina e no Brasil.

É incontestável a legitimidade dos três últimos governos brasileiros na área social e nas melhorias das condições materiais de vida dos setores socialmente mais vulneráveis, num contexto de extraordinário crescimento econômico. No entanto, o princípio estratégico da 
assistência reforça a segmentação da proteção social, e "deixa de fora" uma faixa significativa de pessoas, que não são elegíveis para os programas de assistência focalizada, nem se beneficiam da Previdência social. Esse segmento corresponde a $27,4 \%$ da população ocupada brasileira de 16 a 65 anos $^{16}$, e abarcava quase 24,69 milhões de pessoas desprotegidas socialmente, em 2014, segundo dados da PNAD/IBGE (INFORME..., 2015). São os no man's land de Lautier (1999) que chamo de 'coletivos de destino" (IVO, 2008), ou seja, uma "classe para o outro", utilizando-me de um estudo de Bourdieu (1977) sobre o campesinato. Eles podem ser dimensionados pelos inscritos no CadUnico ${ }^{17}$ - banco de dados de pessoas "elegíveis para os programas sociais", os quais somavam, em 2014, 87 milhões de pessoas na linha da pobreza definida pela Lei Orgânica da Assistência Social (LOAS) e abstraídos os beneficiados pelo Bolsa Família aproxima-se dos 25 milhões de pessoas. Do ponto de vista político, a gestão pública dessa população com vistas à inclusão nos benefícios sociais gera, indiretamente, uma fidelidade passiva entre governo, tecnoburocracia e as classes populares - famílias em situação de pobreza-, desorganizadas e sem outras formas de mediação, senão o gerenciamento do acesso pelo CadUnico para inclusão às políticas e benefícios sociais.

Essa adesão passiva da população de demandantes da assistência em vista da expectativa de inclusão nos programas sociais atesta, nos resultados da eleição de 2014 para a presidência da República, uma adesão de $70 \%$ do eleitorado da região Nordeste à candidata do PT, a Presidente Dilma Rousseff, em todos os estados da Região onde os níveis de pobreza são os mais elevados no País. No entanto, na região Sudeste, onde a opinião pública e a oposição assentam suas bases, esses programas não tiveram a mesma influência. Uma possível explicação para a baixa adesão no Sudeste resulta da prevalência de trabalhadores na faixa de dois salários mínimos, que constitui o segmento menos beneficiado por essas políticas e que enfrentam ainda no cotidiano as dificuldades no acesso a serviços públicos

\footnotetext{
${ }^{16} \mathrm{O}$ total da população ocupada brasileira entre 16 a 65 anos, em 2014, abrangia 90 milhões de pessoas, sendo 50, 5 milhões de homens e 39.5 milhões de mulheres, segundo a PNAD/IBGE.

${ }^{17} \mathrm{O}$ cadastro único (CadUnico) é a porta de entrada para o Bolsa Família e os programas sociais. É uma base de dados das famílias de diferentes municípios, cuja renda deve ser de meio salário mínimo para cada integrante da família ou ganhar até 3 salários mínimos de renda mensal total. O titular do cadastro pode ser qualquer membro da família maior de 16 anos, que tenha CPF e titulo de eleitor. <http://inscricoes2016.com.br/cadastro-unico-2016-cadunico-inscricao-cadastro.html,> Acesso em 22 abr. 2016.
} 
(especialmente transporte e saúde), de baixa qualidade, agravados ainda mais pela crise internacional das commodities, a exemplo do que ocorre no Rio de Janeiro. Ademais, o valor dos benefícios transferidos por esses programas não tem o mesmo impacto no orçamento familiar como ocorre em cidades de pequeno e médio porte. As famílias residentes nessas áreas metropolitanas enfrentam custos de transporte, deslocamento e moradia elevados, que consomem parte relevante da renda familiar.

Portanto, a atenção à pobreza dissociada do universo do trabalho ratifica a segmentação da proteção social e, em áreas onde prevalece o emprego assalariado, como nas grandes metrópoles, não favorece uma maior adesão entre cidadãos e governos. Além disso, nessas regiões, a formalização do mercado de trabalho tem sido acompanhada pelo aprofundamento da precarização das relações de trabalho, a exemplo dos contratos de terceirização, que se traduzem em piores condições de trabalho, salários mais baixos, ampliação das jornadas de trabalho, maior rotatividade no emprego e menor acesso a benefícios (DRUCK; FRANCO, 2011). Essas tendências controversas contribuem também para produzir uma crise de representação entre classes populares, trabalhadores e governos.

Assim, no início de 2015, quando o governo da Presidente Dilma adotou algumas medidas de ajuste fiscal atingindo a legislação trabalhista para o enfrentamento da crise econômica, confirma-se a prevalência de uma estratégia social pró-pobres, já que as medidas de ajuste fiscal propostas naquele momento incidiram sobre os direitos previdenciários e trabalhistas, a exemplo da alteração das regras do seguro-desemprego ${ }^{18}$ e do acesso às pensões e a Lei da Terceirização ${ }^{19}$, mantendo, no entanto, os compromissos com o Bolsa Família, em que pesem pressões da equipe do orçamento para redução de 10 bilhões desse programa, recomendação que não foi acatada pela Presidente ${ }^{20}$ eleita, em 2015. Nesse

\footnotetext{
${ }^{18}$ De acordo com o Ministério da Fazenda, pelas novas regras para acesso ao Seguro-desemprego - Lei n. 13.134 (BRASIL, 2015a): na primeira solicitação, o trabalhador poderá receber quatro parcelas se tiver trabalhado entre 18 e 23 meses nos 36 meses anteriores, quando antes a exigência era de 6 meses anteriores de trabalho. Poderá receber cinco parcelas se tiver trabalhado a partir de 24 meses nos 36 meses anteriores. Já na segunda solicitação, ele poderá receber quatro parcelas se tiver trabalhado entre 12 e 24 meses nos 36 meses anteriores. Outras mudanças afetam o valor da pensão por morte integram um conjunto de medidas provisórias mais rigorosas para acesso de benefícios Previdenciários.

${ }^{19}$ A Câmara dos Deputados aprovou, em pleno contexto de crise (8.4.2016), o projeto de Lei 4330/2004 (BRASIL, 2015b) que regulamenta contratos de Terceirização no mercado de trabalho, que fora reapresentado em 2015, e que havia suscitado inúmeras e serias críticas.

${ }^{20}$ Refiro-me ao contexto de 2015, pois as ações de austeridade dos gastos públicos anunciadas pelo VicePresidente Michel Temer como solução da crise econômica "Travessia social" (FUG,, 2016) projeta uma
} 
sentido, o liberalismo social legitima a segmentação da proteção pró-pobres e tenciona a justiça redistributiva efetivada pelos direitos do trabalho.

Em que pesem os limites desses PTRs, no entanto, ao mudar-se a base social do país no sentido de maior inclusão, muda-se também o patamar da política. Quando 14 milhões de famílias saem da situação de miséria para a linha do consumo torna-se evidente que essa pequena mobilidade atua sobre a subjetividade desses sujeito ${ }^{21}$ e altera as suas expectativas políticas e sociais! Os adultos que vivenciaram o contexto favorável de distribuição de benefícios pelo Estado reconhecem o que essas políticas representaram para suas famílias e são gratos por elas. Os jovens que cresceram no usufruto desses benefícios já os consideram direitos "naturais" e projetam expectativas de mobilidade ascendente como obrigações públicas: acesso à universidade, consumo moderno etc.

Portanto, a mudança na base social pela via do consumo gera autoestímulo e autoreconhecimento pelo consumo e acesso a serviços, como o ensino superior, alterando a base da estrutura social, mas não foi capaz de organizar politicamente essa base. A dinâmica da inclusão se fez pela individualização dos benefícios em termos de consumo, como se pode observar na heterogeneidade das demandas que compuseram as pautas das mobilizações de junho de 2013.

Assim, a vivência institucional das políticas sociais produziu expectativas crescentes de inclusão, direitos e mobilidade social, e novas subjetividades, projetando-se em exigências de serviços de melhor qualidade, como se pode identificar na agenda dos jovens, nas jornadas de junho de 2013. Essas reivindicações iniciaram-se contra o aumento do preço do transporte coletivo urbano e avançou numa crítica mais ampla ao Estado e aos serviços expandindo-se numa pauta de direito à cidade e às condições de usufruto dos bens públicos de qualidade.

A inclusão ao ensino superior via crédito via o Fundo de Financiamento Estudantil FIES ${ }^{22}$ se constituiu outra via de mobilidade social dos jovens, mas, desde 2015, abriu-se em incertezas. Ainda que o valor de financiamento não tenha sido reduzido à época, os

redução e ajuste no Bolsa Família para 5\%., mas por receio de impopularidade, recuou e anunciou um reajuste dos benefícios do programa em 12\%, em 02 de julho de 2016., o maior desde que o programa foi criado.

${ }^{21}$ Considerações feitas por Marcos Nobre em debate no Fórum (2016) "O Futuro do Brasil" promovido pelo CEE da Fiocruz, em 10 de abril de 2016. Disponível em: http://www.cee.fiocruz.br/?q=node/g6

${ }^{22}$ O Fundo de Financiamento Estudantil (Fies) - programa do Ministério da Educação que financia cursos superiores privados. 
estudantes, em reunião na Câmara dos Deputados, reclamavam de dificuldades para acessar o sistema e demonstravam insegurança quanto ao seu acesso e permanência no ensino superior ${ }^{23}$, frustrando expectativas.

\section{Inclusão social, mercado e democracia: as contradições do liberalismo social}

O processo de transição política da Constituição brasileira de 1988 ao contexto atual revela, portanto, diversas contradições e paradoxos. A trajetória recente das políticas sociais aponta para um amplo processo de inclusão social das camadas populares à vida institucional e ao mercado, resultantes de uma ação efetiva do Estado em favor dos estratos de renda mais baixa, viabilizada pelo desenvolvimento de programas de distribuição de renda, aumento do salário mínimo, abertura de crédito popular e inclusão produtiva, acesso à moradia etc., medidas que dinamizaram o mercado interno e alteraram a pirâmide de renda em favor dos estratos de renda mais baixos.

Esse processo é acompanhado de uma vivência controvertida da democracia, que se reafirma como valor moral e base institucional de organização da vida, mas experimenta, na prática, uma inversão de compromissos entre governo e as várias classes sociais, especialmente com os setores médios. Uma primeira contradição se expressa na tendência a priorizar programas de renda às famílias mais pobres ao mesmo tempo em que promove uma desregulação dos direitos sociais e trabalhistas (favorável à agenda de ajustes neoliberal, no âmbito internacional). Por outro lado, as políticas de valorização do salário mínimo e de recuperação dos empregos até 2014 não geraram garantias de proteção ao trabalho, capazes de enfrentar as políticas de austeridade de 2015 em diante. Uma terceira contradição referese à baixa qualidade da oferta de serviços de transporte público, saúde e segurança nas cidades, que corrói os ganhos e a melhoria de renda das famílias nas metrópoles brasileiras, comprometendo a reprodução social de vida e trabalho das camadas populares. Assim, podese arriscar a hipótese de que o colapso nas prestações de serviços de saúde e educação gera um sentimento de inversão dos compromissos entre os cidadãos e os governos, a exemplo

\footnotetext{
${ }^{23}$ Estudantes reclamam de dificuldade de acesso ao FIES em comissão na Câmara. (EBC, 2016). Disponível em: http://www.ebc.com.br/educacao/2015/03/estudantes-reclamam-de-dificuldade-de-acesso-ao-fies-emcomissao-da-camara. Acesso em: 22 abr. 2016.
} 
das condições da oferta da saúde e educação e a contraprestação das famílias na contraprestação das condicionalidades dos programas sociais (Bolsa Família), ou no pagamento de taxas e impostos, levando a uma crise de confiança entre sociedade e governo.

A gravidade das condições de reprodução social dos moradores na área urbana pode ser avaliada pela repercussão que um aumento de apenas 0,20 centavos na tarifa de transportes, em São Paulo, produziu sobre o salário mínimo brasileiro. Calcula-se que para o trabalhador que ganhava apenas o salário mínimo, o custo diário com transporte para o trabalho equivalia, à época, a pouco mais que a quarta parte de sua renda, e isso não é pouco! Em contraposição, a Auditoria Cidadã da Dívida (AUDITORIA, 2016) ${ }^{24}$, com base em dados do Siafi do Orçamento Geral da União 2015 executado (Total = 2,268 trilhão), revela como a política do governo federal privilegia o setor financeiro e não a área social, uma vez que as despesas com juros e amortizações da dívida pública representaram 42,43\% do orçamento nacional, enquanto o governo dedicou à saúde pública apenas 4,3\%, à educação 3,91\%, e ao transporte $0,43 \%$.

Esses dados exibem a assimetria entre gastos com a dívida e gastos sociais, e mostram que as garantias da proteção social ultrapassam muito a dimensão técnica do orçamento ou a provisão de renda e consumo (ainda que o acesso à renda seja incontestavelmente importante numa sociedade profundamente desigual, como a brasileira), mas dependem fortemente de investimentos em serviços públicos de qualidade nas áreas da saúde, educação, transporte, saneamento e segurança. Ou seja, os direitos da cidadania se materializam e efetivam, também, no usufruto de bens públicos na forma de serviços, e esses dependem da política, no âmbito interno e internacional.

Desde 2010 a evolução do PIB brasileiro apresenta tendência à desaceleração, quando o PIB cresceu 7,5\% em comparação ao ano anterior (2009), e, desde então passou a variações declinantes: 3,9\% (2011), 1,9\% (2012), 3,0\% (2013) e 0,1\% (2014). Apesar das inúmeras medidas e incentivos criados pelo governo, ${ }^{25}$ a redução dos investimentos repercutiu no

${ }^{24}$ A Auditoria Cidadã da Dívida é um movimento aberto à participação de todos os cidadãos e entidades da sociedade civil que desejam conhecer a realidade financeira do País e saber a verdadeira natureza do endividamento público. Disponível em: <http://www.auditoriacidada.org.br/>.

25 Programas de moradia "Minha Casa Minha Vida"; desoneração das empresas; redução das tarifas de energia; redução da taxa básica de juros entre outras. 
aumento do desemprego e a economia nacional não tomou o impulso desejável, desde o final do governo Dilma (DIEESE, 2016).

A política de desoneração fiscal adotada pela presidente Dilma Rousseff em favor do empresariado industrial, inicialmente pensada como política desenvolvimentista de garantia do emprego produziu uma perda severa de arrecadação do governo ${ }^{26}$, subtraindo $25 \%$ da receita federal e produzindo uma drástica transferência de renda para as elites empresariais (FSP, 2015). Essa desoneração fiscal para as empresas, sem condicionalidades, foi absorvida pelos empresários como 'ganhos', e não inibiu politicamente a demissão dos trabalhadores, e tampouco resolveu a crise de confiança entre as elites empresariais e o governo.

A taxa de desemprego no Brasil ao final do trimestre encerrado em agosto de 2016 foi de $11,8 \%$ segundo dados do Instituto Brasileiro de Geografia e Estatística - IBGE, atingindo 12 milhões de pessoas, mas manteve invariável o rendimento médio do trabalhador, em $\mathrm{R} \$$ 2.011 no trimestre completado em agosto deste ano. Em comparação com o mesmo período em 2015, o crescimento na população desocupada no trimestre encerrado em agosto de 2016 foi de $36,6 \%$, ou 3,2 milhões de pessoas. Os setores que apresentaram maior redução de ocupados foram eminentemente urbanos: a construção civil 3,3\%, (249 mil pessoas); o setor de serviços domésticos, com 2,8\% (177 mil pessoas) e, em terceiro lugar, a população ocupada na indústria, que caiu 1,9\%, (229 mil pessoas) (FSP, 2016b). A taxa geral de desemprego do segmento jovem, no entanto, é alarmante, chegando em 2017, segundo a OIT, a 30\% dos jovens brasileiros (ESTADÃO, 2017). ${ }^{27}$

Essa experiência controvertida de aumento do desemprego dos jovens, a baixa qualidade na oferta da saúde e educação, a queda da renda, os juros elevados etc. radicalizam-se no contexto imediatamente pós-eleição 2014. O ambiente econômico recessivo, a tentativa de equilibrar as contas públicas, adotando uma agenda de ajustes, além dos graves escândalos de corrupção, que envolveu também políticos da base do

\footnotetext{
${ }^{26}$ Segundo cálculos de auditores fiscais para a Folha de São Paulo, as desonerações de tributos concedidas pelo governo da presidente Dilma Rousseff desde 2011 somarão cerca de $\mathrm{R} \$ 458$ bilhões em 2018, quando termina (ria) o atual mandato. Considerando que o programa Bolsa Família foi orçado em $\mathrm{R} \$ 27,1$ bilhões em 2015, o valor total das desonerações ao setor empresarial custearia inteiramente o Bolsa Família por 17 anos seguidos (FSP, 6.9. 2015).

${ }_{27}$ Dados apresentados pela Organização Internacional do Trabalho (OIT) apontam que, ao final de 2017, praticamente $30 \%$ dos jovens brasileiros estariam sem trabalho. "Trata-se da maior taxa desde 1991", aponta a entidade, com sede em Genebra (ESTADÃO, 20 nov. 2017).
} 
governo, deslegitimam o governo e rompem afinidades e compromissos do governo com os trabalhadores já que a agenda de ajuste compromete direitos trabalhistas e estimula políticas repressivas sobre a força de trabalho, aprofundando as condições de precarização do trabalho e reprodução da vida.

Com essas contradições e mudanças, como as políticas sociais podiam legitimar o governo? Que acomodações ocorreram entre as classes? Como já analisado, as políticas voltadas para os segmentos mais pobres não obtiveram a mesma legitimidade entre as classes médias e altas da região Sudeste, onde o candidato do PSDB foi vitorioso, nas eleições presidenciais de 2014. O candidato da oposição obteve 51 milhões de votos, dos quais, cerca de 30 milhões eram eleitores das classes populares. Por outro lado, as velhas oligarquias agrárias que integram o bloco do agronegócio no Congresso Nacional, estavam sendo afetadas pela queda no preço internacional das commodities e sentiam-se ameaçadas pelas denúncias de corrupção. Essas perdas e ameaças aprofundaram a tensão das velhas/novas oligarquias agrárias em relação ao governo do $\mathrm{PT}$, apesar dos ganhos que obtiveram durante esses governos com os elevados preços das commodities e o apoio do governo Dilma ao Plano Safra.

Curioso é que a maior parte das operações de crédito (chamadas de "Pedaladas fiscais") que constituíram a base técnica para o pedido e para a aprovação do impeachment da Presidente Dilma sem mérito constitucional, baseou-se no pagamento do crédito agrícola do Plano Safra ${ }^{28}$ por bancos oficiais, beneficiando exatamente esse segmento agrário. Importante destacar que o Ministério Público no Distrito Federal não reconheceu nesses atos alegados um ilícito penal, mas apenas um ato de improbidade administrativa. Mesmo assim, esse reconhecimento não conseguiu reverter a decisão política daqueles que pressionaram para o impedimento da Presidente, e que aprovarem o seu afastamento definitivo da presidência da República em 31 de agosto de 2016 (BRASIL, 2016), configurando um golpe legislativo, já que não ficou evidenciado o alegado crime de responsabilidade fiscal.

${ }^{28}$ O Governo atrasou o repasse de 3,5 bilhões de reais ao Banco de Brasil para pagamento do programa de crédito agrícola (Plano Safra). Com o atraso, o Banco do Brasil pagou os agricultores com recursos próprios. (REDAÇÃO do G1, de 27 jun. 2016). Perícia conclui que Dilma não participou de pedaladas fiscais.. Acesso em 11 de nov. 2016. 
O mais escandaloso dessa decisão é que apenas dois dias após o impeachment da Presidente Dilma Rousseff, em 02 de setembro de 2016, o Congresso Nacional aprovou a Lei 13.332/2016 que flexibiliza e, portanto, reconhece legalidade das operações e regras para abertura de créditos suplementares sem necessidade de autorização do Congresso, tornando o que foi considerado um ilícito pelas forças do gole e da chantagem do legislativo, um procedimento normal admitido e permitido ao novo governo do Michel Temer, revelando o caráter imoral na destituição da Presidente da República num aberto desrespeito ao resultado das eleições soberanas de 2014 pelos que armaram a destituição da presidente.

A convergência da crise econômica com a crise institucional consolida uma retomada radicalizada do diagnóstico conservador dos anos 70 relativo à "crise de autoridade do governo", justificando saídas antidemocráticas no desmantelamento das políticas distributivas constitucionais dos últimos anos, pela Proposta de Emenda Constitucional (PEC) 241, aprovada em segundo turno no Congresso Nacional, em 25 de outubro de 2016, que congelou por 20 anos os gastos sociais do Governo Federal, a despeito do parecer contrário da Procuradoria Geral da República, em Nota 82, de 2016:

A PEC 241 institui o 'Novo Regime Fiscal' pelos próximos vinte anos, prazo longo o suficiente para limitar, prejudicar e enfraquecer o desempenho do Poder Judiciário e demais instituições do Sistema de Justiça [...] e, nesse alcance, diminuir a atuação estatal no combate às demandas de que necessita a sociedade, entre as quais: o combate à corrupção; o combate ao crime; a atuação na tutela coletiva; e a defesa do interesse público" (BRASIL, 2016b, p. 6).

Nessa Nota, o Ministério Público alega que a PEC 241, como foi enviada ao Congresso Nacional, transforma o Executivo em um "[...] "super órgão" que, a pretexto de trazer a trajetória da dívida pública para níveis sustentáveis, passará a controlar os demais poderes, ainda que de maneira indireta [...]" (p. 9). Essa Proposta de Emenda Constitucional, segundo interpretação nossa, fere direitos fundamentais e atribui ao Executivo um poder discricionário perigoso, limitando a capacidade de negociação entre cidadania e governo. ${ }^{29}$

\footnotetext{
29 A PEC 241 assumiu o número PEC 55/2016 no Senado, e após aprovada foi promulgada pela Emenda
} Constitucional n. 95, de 15.12.2016 (BRASIL, 2016). 


\section{Conclusões}

A seguir apontam-se algumas assimetrias no percurso entre economia, democracia social e política:

a) Os movimentos sociais dos anos 1970 e a luta pelo restabelecimento da democracia contribuíram para a afirmação de valores republicanos (de igualdade, direitos sociais, individuais e coletivos, uma forte competitividade eleitoral e uma participação política elevada). Entretanto, as políticas neoliberais de austeridade fiscal e privatização dos serviços públicos nos anos 1990 resultaram numa incompatibilidade entre as políticas redistributivas e a democracia, afetando especialmente os segmentos assalariados urbanos e as classes médias, em relação aos direitos sociais.

b) O princípio ordenador das políticas sociais a partir dos anos noventa se fez prioritariamente pela expansão de programas estratégicos de assistência focalizada de transferência de renda aos extremamente pobres, fora do mercado de trabalho, em áreas que, para os liberais, não afetam as "zonas críticas" da proteção social e a matriz securitária do trabalho, foco central da investida da reforma ultraliberal, além da privatização dos bens públicos para os setores privados internacionais.

c) A queda do preço das commodities no mercado internacional, afetando o PIB de diversos municípios produziu um ambiente de crise das áreas metropolitanas, que foram acompanhadas pela incapacidade de atendimento dos serviços públicos na área de educação, saúde de baixa qualidade, além de transportes e segurança pública, produzindo uma inversão entre direitos e deveres da cidadania, entre as contrapartidas dos beneficiários e as contraprestações do Estado produzindo uma crise de representação entre os cidadãos e a política, e um esgarçamento nas relações entre a sociedade, o Estado e os governos.

d) A polarização política, aprofundada com o golpe parlamentar contra a Presidente Dilma Rousseff aprofundou a crise econômica, aumentou a dívida pública em 2016, e fomentou saídas autoritárias de desvinculação constitucional das despesas obrigatórias e trabalhistas, em favor do setor financeiro. As reformas constitucionais aprovadas rapidamente afetaram drasticamente os direitos dos 
trabalhadores e os direitos sociais instituídos na Constituição de 1988, alterando o pacto social prevalecente, caracterizando uma ruptura de contrato com os direitos da cidadania.

e) A desregulação dos direitos sociais constitucionais, portanto, caracteriza portanto uma moratória social ("quebra de contrato") do governo com os seus cidadãos, colaborando para aprofundar a crise política, institucional e de confiança, quando opera uma violenta transferência de renda nacional para os setores rentistas (FSP, 2016a), com ruptura drástica dos fundamentos sociais do Estado, supressão de direitos do trabalho, e reativação de instrumentos repressivos sobre o trabalho, num contexto em que as regras formais de justiça oscilam e a democracia assume um caráter meramente formal, dissociadas da democracia social.

f) Essa dissociação expressa regimes autoritários de aparência democrática, que seguem regras procedimentais e, muitas vezes seletivas, mas produzem uma profunda exclusão social, e uma espoliação de recursos naturais em favor do capital rentista, além da destituição das garantias dos cidadãos aos direitos sociais e ao trabalho. Boaventura de Souza Santos considera essas sociedades como politicamente democráticas, mas "socialmente fascistas", já que tendentes à exclusão dos direitos sociais da grande maioria. Compartilho com esse autor de que a saída para esse quadro implica a refundação da democracia, como alternativa para as crises contemporâneas, com o estabelecimento de novos pactos na democratização do poder. Portanto, ao contrário do que quer a doutrina neoliberal no presente, o ponto dessa mudança está exatamente em mais democracia. ${ }^{30}$

\section{Referências}

AUDITORIA Cidadã da Dívida. Explicação sobre o gráfico do orçamento, 2016. Disponível em: <http://www.auditoriacidada.org.br/blog/2016/11/og/explicacao-sobre-o-grafico-do-orcamentoelaborado-pela-auditoria-cdada-da-divida/>. Acesso em 20 de novembro de 2016.

\footnotetext{
$3^{\circ}$ Conforme exposição que fiz no Seminário da Pré-Alas em julho de 2017, UNB/ALAS, Brasília. Aceito para publicação sob o título IVO, Anete B. L. Democracia e desenvolvimento na América Latina. In: BARROS, Flávia Lessa (Org.). As encruzilhadas da América Latina: a Sociologia em tempos de mudança. Brasília: Editora UNB/ALAS (prelo 2018).
} 
BOURDIEU, Pierre. Une classe objet. Actes de la Recherche en Sciences Sociales. Paris: EHESS, p.17-18, 1977.

BRASIL. Câmara dos Deputados. Projeto de Lei 4.330/ 2004. Projeto de Lei da Terceirização. Brasília, 22 abr. 2015b. Disponível em:

$<$ http://www.camara.gov.br/proposicoesWeb/fichadetramitacao?idProposicao=267841 $>$ Acesso em: 20 abr. 2016.

BRASIL. Discurso da Presidenta da República, Dilma Rousseff, durante celebração dos 10 anos do Programa Bolsa Família. Brasilia-DF, 30 de out. 2013. Disponível em: http://www2.planalto.gov.br/acompanhe-oplanalto/discursos/discursos-da-presidenta/discurso-da-presidenta-da-republica-dilma-rousseffdurante-celebracao-dos-10-anos-do-programa-bolsa-familia-brasilia-pdf. Acesso em: 16 jul. 2014.

BRASIL. Emenda Constitucional n. 95, de 15 de dezembro de 2016. Altera O Ato Das Disposições Constitucionais Transitórias, Para Instituir O Novo Regime Fiscal, E Dá Outras Providências. Brasília, 2016a. Disponível em < http://legis.senado.leg.br/legislacao/DetalhaSigen.action?id=540698> Acesso em junho de 2017.

BRASIL. Presidência da República. Lei 8.742, de 7 de dezembro de 1993. Lei Orgânica da Assistência Social. Disponível em:

<http://www.planalto.gov.br/ccivil_03/Leis/L8742compilado.htm>. Acesso em: fev., 2007.

BRASIL. Presidência da República. Lei no 13.134, de 16 de junho de 2015a. Lei do seguro desemprego. Disponivel em < http://www.planalto.gov.br/ccivil_03/_ato2015-2018/2015/lei/L13134.htm> Acesso em: 20 abr. 2016.

BRASIL. Procuradoria Geral da República (PGR). Nota Técnica PGR/SRI No 82/2016. Brasília, 2016b. Disponivel em: <http://www.mpf.mp.br/pgr/documentos/nota-tecnica-pgr-sri-no-082-2016-pgr002906o9-2016.pdf $>$. Acesso em: 19 nov. 2016.

BRASIL. Tribunal de Contas da União (TCU). Relatório de Acompanhamento do Programa Bolsa Família. n. 022.093.2006-5. Brasília, 2006.

COMISIÓN ECONÓMICA PARA AMÉRICA LATINA Y EL CARIBE (CEPAL). Desarrollo social inclusivo. Una nueva generación de políticas para superar la pobreza y reducir la desigualdad en América Latina y el Caribe. Santiago de Chile: CEPAL, 2015

CORREA, Diego. Seminário: Pesquisador analisa influência dos programas de transferência de renda no eleitor. Entrevista concedida ao Centro de Política e Economia do Setor Público (CEPESB). Notícias. São Paulo, mar. 2014. Disponívelem: https://cepesp.wordpress.com/2014/03/29/seminariopesquisador-analisa-influencia-dos-programas-de-transferencia-de-renda-no-eleitorl Acesso em: abr. 2016.

DEPARTAMENTO INTERSINDICAL DE ESTATÍSTICAS E ESTUDOS SOCIOECONÓMICOS (DIEESE). Boletim de Conjuntura, n. 6, mar. 2016. Disponível em: https://www.dieese.org.br/boletimdeconjuntura/2016/boletimConjunturaoo6.pdf Acesso em: mar. 2016.

DRUCK, Graça; FRANCO, Tânia. Trabalho e Precarização Social - Introdução. Caderno CRH, v. 24, p. 9-12, n. SPE., 2011.

EMPRESA BRASILEIRA DE COMUNICAÇÕES (EBC). Estudantes reclamam de dificuldade de acesso ao Fies em comissão na Câmara. EBC Portal. Disponível em: 
http://www.ebc.com.br/educacao/2015/03/estudantes-reclamam-de-dificuldade-de-acesso-ao-fiesem-comissao-da-camara. Acesso em 22 abr. 2016

ESPING-ANDERSEN, Gosta. Fundamentos sociales de las economías postindustriales. Barcelona: Editorial Ariel, 2000.

ESPING-ANDERSEN, Gosta. The three worlds of welfare capitalism. Cambridge: University Press, 1990.

ESTADÃO. Desemprego entre jovens no Brasil tem maior taxa em 27 anos, diz OIT. São Paulo, 20 nov. 2017. Disponível em < https://economia.estadao.com.br/noticias/geral,desemprego-entrejovens-no-brasil-tem-maior-taxa-em-27-anos-diz-oit,70002091029>. Acesso em 4.12.2017.

FOLHA DE SÃO PAULO (FSP). Desemprego sobe 11,8\% e atinge 12 milhões de pessoas, diz o IBGE. São Paulo, 30 set. 2016, 2016b. Disponível em <http://www1.folha.uol.com.br/mercado/2016/og/1818323-numero-de-desempregados-atinge-12mi-no-trimestre-encerrado-em-agosto.shtml> Acesso em: 20 nov. 2016.

FOLHA DE SÃO PAULO (FSP). Dilma deu R $\mathbf{4 5 8}$ bilhões em desonerações. São Paulo, Brasil, 6 set. 2015. Disponível em <http://www1.folha.uol.com.br/mercado/2015/og/1678317-dilma-deu-r458-bilhoes-em-desoneracoes.shtml>. Acesso em: 24 abr. 2016.

FOLHA DE SÃO PAULO (FSP). Dívida pública é bomba relógio que cresce 2 bilhões por dia. São Paulo, 24 abr. 2016, 2016a. Disponível em

<http://www1.folha.uol.com.br/mercado/2016/04/1764093-divida-publica-e-bomba-relogio-quecresce-cerca-de-r-2-bilhoes-por-dia.shtml?cmpid=newsfolha>. Acesso em: 24 abr. 2016.

FOLHA DE SÃO PAULO (FSP). População Brasileira atinge 202,7 milhões de habitantes, calcula o IBGE. São Paulo, 28 ago. 2014. Disponível em http://www1.folha.vol.com.br/cotidiano/2014/08/1507099-populacao-brasileira-atinge-2027milhoes-de-habitantes-calcula-ibge.shtml Acesso em: 20 jan. 2016.

FÓRUM "O FUTURO DO BRASIL". Rio de Janeiro, CEE da Fiocruz. Postado em: 10 abr. 2016. Disponivel em: http://www.cee.fiocruz.br/?q=node/g6. Acesso em: 10 abr. 2016.

FREIRE, Paulo. Pedagogia do oprimido. Rio de Janeiro: Paz e Terra, 1987.

FUNDAÇÃO ULISSES GUIMARÃES (FUG). A Travessia Social. Uma Ponte para o Futuro. (Plano Temer- Vice-Presidente). PMDB: Brasília, 01 mai. 2016. Disponível em: https://complemento.veja.abril.com.br/pdf/travessia\%2osocial\%20\%20pmdb livreto_pnte_para_o futuro.pdf Acesso em: 02 mai. 2016.

FUNDAÇÃO ULISSES GUIMARÃES (FUG). Uma Ponte para o Futuro. PMDB. Brasília, 29 out. 2015. Disponivel em: https://www.fundacaoulysses.org.br/wp-content/uploads/2016/11/UMA-PONTEPARA-O-FUTURO.pdf Acesso em: 05 abr. 2016.

G1. Redação. Edição de 27 de jun. 2016. Perícia conclui que Dilma não participou de pedaladas fiscais. Disponível em: $<$ http://g1.globo.com/jornal-nacional/noticia/2016/06/pericia-conclui-que-dilma-naoparticipou-de-pedaladas-fiscais.html> Acesso em: 11 nov. 2016.

HAAS, Peter. Introduction: epistemic communities and international policy coordination. International Organization. Cambridge University Press, v. 46, n. 1, p. 1-35, Winter, 1992. 
HIGGINS, Robert R. The Welfare State in Crisis: An Account of the Conference on Social Policies in the 1980s. By the ORGANISATION FOR ECONOMIC CO-OPERATION AND DEVELOPMENT (OCDE). (Paris: Organisation for Economic Co-operation and Development, 1981, p. 273, paper). American Political Science Review. Paris, v. 77, n. 3, p. 785-786, 1983.

HUNTINGTON, Samuel; CROZIER, Michel y WATANUKI, Joji. The crises of Democracy. Report on the Governability of Democracies to the Trilateral Commission. New York: New York University Press, 1975 .

INFORME da Previdência. Evolução Recente da Proteção Previdenciária e seus Impactos sobre o Nível de Pobreza. Informe de Previdência Social, v. 27, n. 11, nov. 2015.

INSTITUTO DE PESOUISAS ECONÔMICAS APLICADAS (IPEA). A década inclusiva (2001-2011): desigualdade, pobreza e políticas de renda. Comentário Ipea. Brasília, n. 155, 25 set. 2012.

IVO, Anete B. L. A reconversão do social: dilemas da redistribuição no tratamento focalizado. São Paulo em Perspectiva. São Paulo, SEADE, v. 18, n. 2, p. 57-67, abr./jun., 2004.

IVO, Anete B. L. Democracia e desenvolvimento na América Latina. In: BARROS Flávia Lessa (Org.) As encruzilhadas da América Latina: a Sociologia em tempos de mudança. Brasilia: Editora UNB/ALAS (prelo) [2018?].

IVO, Anete B. L. Metamorfoses da questão democrática: governabilidade e pobreza. Buenos Aires: CLACSO, 2001.

IVO, Anete B. L. Viver por um fio: pobreza e política social. São Paulo: Annablume; Salvador: CRH/UFBA, 2008.

LAUTIER, Bruno. Les politiques sociales en Amérique Latine. Propositions de méthode pour analyser en écaltement en cours. Cahiers des Amériques Latines. Paris: IHEAL Editions, n. 30, p.19- 44, 1999.

LULA DA SILVA, Luis Inácio. Carta ao Povo Brasileiro. São Paulo, 22 de jun. 2002. Disponível em: http://csbh.fpabramo.org.br/uploads/cartaabertaaopovobrasileiro.pdf Acesso em 15 de abril de 2015.

OFFE, Claus. Capitalismo desorganizado. Transformações contemporâneas do trabalho e da política, São Paulo, Editora Brasiliense, 1989.

OFFE, Claus. Problemas estruturais do Estado capitalista. Tradução Bárbara Freitag. Rio de Janeiro: Tempo Brasileiro, 1984 .

PRZEWORSKI, Adam. Capitalismo e social-democracia. São Paulo: Companhia das Letras, 1989.

RANCIÈRE, Jacques. La mésentente: politique et philosophie. Paris: Galilée, 1995. [0

Desentendimento: Política e Filosofia. Trad. Ângela Leite Lopes. São Paulo: Ed. 34, 1996.

SOUZA SANTOS, Boaventura. A difícil reinvenção da democracia frente ao fascismo social. Entrevista concedida a Ricardo Machado. Revista IHU UNISINOS [on line]. São Leopoldo, 8 dez. 2016. Disponível em: http://www.ihu.unisinos.br/159-noticias/entrevistas/563035-a-dificil-reinvencao-da-democracia-frente-aofascismo-social-entrevista-especial-com-boaventura-de-sousa-santos>. Acesso em: 05 jan. 2018.

WEBER, Max. A ética protestante e o "espírito" do capitalismo. Trad. José Marcos Mariani de Macedo. São Paulo: Companhia das Letras, [1904-5] 2004. 
Anete B. L. Ivo

Doutora em Sociologia pela Universidade Federal de Pernambuco, mestre em Ciências Sociais pela Universidade Federal da Bahia (1975) e em Sociedades Latino Americanas pela Université de Paris III (1980). É professora no Programa de Pós-Graduação em Políticas Sociais e Cidadania (UCSAL) e no Programa de Pós-Graduação em Ciências Sociais (UFBA). Atualmente é Fellow do Comparative Research Programme on Poverty (CROP), do International Social Science Council - ISSC- indicada para mandato de 2014 a 2018. E-mail: anetivo@hotmail.com 